\title{
Flowering phenology and floral visitors of Piliostigma reticulatum in a tropical dry forest, Burkina Faso
}

\author{
Madjelia Cangrè Ebou DAO ${ }^{1 *}$, Boukary Ousmane DIALLO ${ }^{1}$ and \\ Chantal KABORE-ZOUNGRANA ${ }^{2}$ \\ ${ }^{1}$ Centre National de la Recherche Scientifique et Technologique / Institut de l'Environnement \\ et de Recherches Agricoles; 03 BP 7047 Ouagadougou, Burkina Faso. \\ ${ }^{2}$ Université Polytechnique de Bobo Dioulasso 01 BP 1091 Bobo Dioulasso 01, \\ Bobo Dioulasso, Burkina Faso. \\ *Corresponding author; E-mail: dao.ebou@yahoo.com; Tel: (226) 70266509
}

\begin{abstract}
Piliostigma reticulatum is a dioecious species that provides food, fodder and the revenues from the sale of its pods constituted an important resource for sahelian population. During the flowering, flowers are abundant but the fruit set remained very low in spite of a large number of insect visitors. The aim of this work was to study flowering phenology, to identify potential pollinators and visitors, to determine the visitation rate and the synchronism between floral phenology and the insect visitors. The natural population studied is located at Budtenga in the North Sudanian area of Burkina Faso. The phenological study was carried out from July 2009 to December 2009 on 500 inflorescences randomly sampled from inflorescences of 40 male and female individuals. Potentials pollinators were determined using their physical ability to carry pollen in their body and the reference based diets. Our results showed that many orders of insects visit the flowers of $P$. reticulatum. Nymphalidae (Lepidoptera), Syrphidae (Diptera), Apidae (Hymenoptera) and Sphecidae (Hymenoptera) were regarded as main potential pollinators of $P$. reticulatum. Apidae (Apis mellifera) was the most abundant and frequent visitor. We found that August was the peak flowering period for both male and female individuals and the peak emergence of potential pollinators. Therefore, the emergence of potential pollinators responsible for pollen dispersal might be punctuated by flowering phenology.
\end{abstract}

(C) 2014 International Formulae Group. All rights reserved.

Keywords: Caesalpinioideae, $P$. reticulatum, phenology, visitors, Sudanian forest.

\section{INTRODUCTION}

Bees and other insect flower visitors need a continuous food supply throughout their whole life cycle. Pollen and nectar provide the complete diet for both the adults and their larvae. The investigations of plant species as food for pollinators are important. Include in the investigations are flowering phenology, nectar secretion, and pollen production (Hedhly et al., 2008). The characteristics of the flowering phenology of a population may have an impact on the attractiveness of insect visitors (Denisow, 2009) and a critical effect on reproductive success including flowering start date, flowering peak date, and flowering duration (Ollerton et al., 2011). However, the use of these descriptors of flowering phenology is of questionable validity, since selection may be acting on other aspects of phenology such as synchrony, and may be constrained by other plant characteristics, such as size (Caban FJ and Melendez-Ackerman, 2007). Synchronized flowering or fruiting phenology 
may be advantageous because they satiate predators or because they attract pollinators and seed dispersers. On the other hand, asynchrony could be also advantageous: plants whose flowers open (or fruits ripe) when flowers (or fruits) are relatively scarce in the population may have better access to pollinators, seed dispersers or any abiotic keyfactor (Diallo et al., 2008). In cross-pollinated species, selection is generally expected to favor synchrony of flowering among individuals, though asynchrony may be favored in populations with intense withinspecies competition for pollinators (Bawa and Buckley, 1989).

Piliostigma reticulatum (D.C.) Hochst species is known as food plants for visitors (Yelemou, 2009). It is a dioecious species used in Burkina Faso for its pods as a supplementary diet to feed livestock during the long period of drought. Very common in the natural population and in the parklands, the female and male individuals produce abundant flowers but fruit yield remains low and poor quality (Dao, 2010). Three hypotheses may explain the poor performance of trees: (i) the absence of synchronism between male and female during flowering, (ii) the long duration of flowering time, (iii) the abundance of visitors ineffective in pollen removal and deposition. The main objective of the study was to examine the pattern of flowering phenology of $P$. reticulatum, to determine visitors and potential pollinators, and the synchronism of flowering between male and female individuals in the population and the insect visitors.

\section{MATERAILS AND METHODS Study area}

The study was conducted in Budtenga village (Burkina Faso) from July to December 2009 in a natural population of $P$. reticulatum. This site located in the north Sudanian zone at $40 \mathrm{~km}$ east of Ouagadougou $\left(12^{\circ} 29^{\prime} \mathrm{N} 1^{\circ}\right.$ $15^{\prime} \mathrm{W}$ ) is subject to a tropical climate with two main seasons, cold dry and hot wet, ranging respectively from October to April and May to September (Guinko and Fontes, 1995). The mean annual rainfall is between 600 and 900 $\mathrm{mm}$, the annual mean temperature is $29.5{ }^{\circ} \mathrm{C}$ and the soil is mainly a ferruginous tropical loamy soil (Ibrahim et al., 2012).

\section{Study material}

The study was conducted in a natural population of $P$. reticulatum at Budtenga where we could expected sampling a maximum of blooming male and female individuals. The population area was estimated at 3.15 ha with 153 trees/ha. We monitored 483 trees on 2009 characterized by individuals bearing flowers and those without flowers. We were considered in this study only the individuals with flowers. Both female and male individuals produce white with pink striped flowers (Arbonnier, 2009). Inflorescences are axillary or terminal panicles and range from $5-15 \mathrm{~cm}$ in long. The mature fruit can stay long on the tree.

\section{Data collections \\ Flowering phenology}

During the growing seasons, detailed observations of the flowering were conducted. The onset and length of the blooming period were recorded. After a preliminary investigation, protocols described by Diallo et al. (2008) were applied. Three phenological flowering stages were determined including the following: (i) stage 1: flowers buds with petals tightly closed (ii); stage 2: fresh, fully opened flowers and (iii) stage 3: setting stage with anthers wilted, petals gone and flowers off. The phenological stage was recorded from July to December 2009 on 20 male individuals and 20 female individuals. We randomly selected five flowering branches per individual at the early stage of the flowering and five inflorescences from down to top of each branch. A total sample of 500 inflorescences of male individuals and 500 inflorescences of female individuals were recorded and every three days the number of unopened flowers, opened flowers and fruit set per inflorescence was counted. The duration of blooming (beginning, full, and terminal) of male and female individuals within the population and the flowering synchronism of male and female individuals were recorded. The blooming duration was determined according to an assumption that it was the moment when at individual level, 5 to 
$95 \%$ of the opened flowers were blooming on a given branch.

\section{Floral insects}

All the diurnal visitors were collected on the opened flowers on one week over two from July to September. Observations were made in the morning from 6 am to $10 \mathrm{am}$, during the sunny time from $10 \mathrm{am}-4 \mathrm{pm}$ and the dusk time from $4 \mathrm{pm}$ to $6 \mathrm{pm}$. Each individual was observed for 20 minutes for every observation day by standing quietly next to the target individual and recording the visiting species, and counting their visitation frequency. Two persons stood on opposite sides of the individual for this purpose. In cases where we could not identify the visitor in the field, it was collected using white net trap for identification. The collected specimens were kept in $70 \%$ alcohol solution. Most of the collected flower visitors were identified to family level using the publications of Chinery (1986) and Picker et al. (2004), and by insect experts from the Laboratory of Forest Entomology of INERA (Institut de l'Environnement et de Recherches Agricoles). The identification was based on the following criteria: the presence or absence of wings, the morphology of the body and legs, the size of the insect, morphology and structure of wings, the characteristics of the mouthparts, the morphology and size of antennas. For families classification the following criteria were used: the presence of two or three cerci, the presence or absence of hind wings and their scale, the size and the wings structure (ribs). To determine the potential pollinators, two complementary approaches were used: the body morphology (presence or absence of hair on the body) and literature-based diets.

The percentage of visits of the potential pollinators was determined during the abundant blooming from 6 am to $6 \mathrm{pm}$ and for 10 consecutive days on August 2009.

\section{Data analysis}

Data are presented as means with Standard Deviation (SD). The analyses were performed using Excell ver. 7.0. The mean flowering duration, the mean number of unopened flowers, opened flowers and fruit set per inflorescence and per sex were calculated. A data table was drawn to show the presence/absence of insect family by order. Then, the visitation rate of potential pollinators was calculated.

\section{RESULTS}

\section{Flowering phenology}

During the study period, $P$. reticulatum individuals started blooming at Budtenga on July. The male individuals bloomed 10 days to two weeks earlier than female ones (Figures 1 and 2). The flowering began in mid-July for the male individuals or in late July for the female ones and lasted till October $28^{\text {th }}$ for both individuals. The flowering duration was 12 weeks for male and 10 weeks for female individuals. The flowering peak occurred in August for both sexes. The mean of opened flowers by inflorescence was important during August. Flowers abortions are very important for man individuals (Figures 1 and 2) and only few were opened in a day (less than 2).

Fruit set began at early August for both sexes. The mean number of ripe pods was less than 2 per inflorescence for female and null for male trees (Figures 1 and 2). Fruiting occurred from August to December in female trees.

\section{Flower insect visitors Visitors}

$P$. reticulatum flowers attract different insect visitors (Table 1). Ten (10) orders were collected including 31 identified to the level of the family, 16 identified to the level of the genus and 23 identified to the level of the species.

Under favorable weather conditions, insects started to visit flowers in the early morning hours. The highest number of insects was present between 11.00 and 15.00. The Dipterans and Bombus spp. were the first to start visiting at around $7.00-8.00$. The activity pattern of flies picked up in the morning and in the early afternoon. The highest number of bumblebees was recorded at 8.00 and 19.00. Apis mellifera was active from 8.00 with three peak periods. The activity pattern of these visitors the orders Hymenoptera, Diptera, Coleoptera, Lepidoptera, Orthoptera and Hemiptera 
were the most important (Figure 3) and most frequent insects collected (Figure 4) during the target period. Within these orders, we noticed that the families Ichneumonidae, Apidae and Vespidae (Hymenoptera), the families Muscidae and Syrphidae (Diptera), the families Lycidae, Meloidea and Scarabaeidae (Coleoptera) the families Acraeidae and Nymphalidae (Lepidoptera), Acrididae (Orthoptera) and Coreidae (Hemiptera) were prevalent during the period of observation (Figure 5).

\section{Potential pollinators}

Insects visitors of $P$. reticulatum were divided into functional groups based on the ability to transfer pollen and diet references. Nymphalidae, Syrphidae and Apidae were the most prevalent families from the beginning (July) to the end of flowering (September). Sphecidae was present during the period of flowering peak (August) (Figure 6). Nymphalidae, Syrphidae, Sphecidae and Apidae were dependent of floral rewards and their bodies were equipped to carry pollen. They were identified as the main potential pollinators of $P$. reticulatum.

Visitation rates

The emergency of the identified potential pollinators began since the beginning of flowering of $P$. reticulatum (Figure 6). The total number of visits per day was 109; 26; 15 and 7 respectively for Apidea, Nymphalidae, Syrphidae and Sphecidae families. During $6-8$ am; 8 - 10 am; 10 - 12 am; 12 -2 pm; 2 - 4 pm and 4 -6 $\mathrm{pm}$, Apidae had the higher number of visits which was respectively $28 ; 46 ; 19 ; 11 ; 2$ and 3 visits (Figure 7). Thus Apidae account for $69.4 \%$ of total visits, Nymphalidae $16.6 \%$; Syrphidae $9.6 \%$ and Sphecidae $4.5 \%$. We observed that Apidae remained more active in early hours than the other families. The activity of all potential pollinators decreased after $2 \mathrm{pm}$ and was null at dusk hours (Figure 7). In spite of the low percentage of total visit of some visitors, we observed that there was temporal overlapping of the potential pollinator's activity during the observation period.

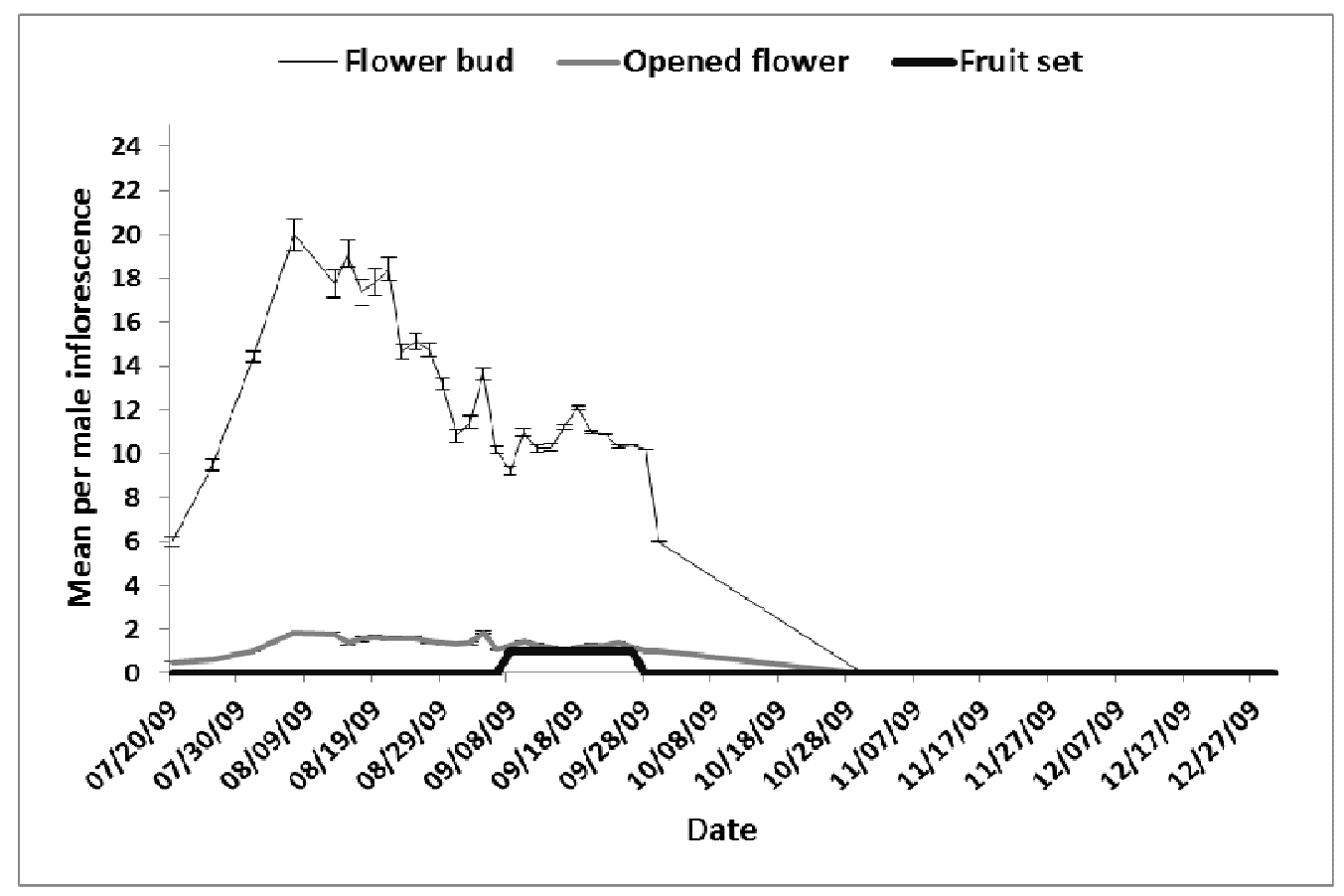

Figure 1: Evolution of flowering and fruiting in male individuals. 


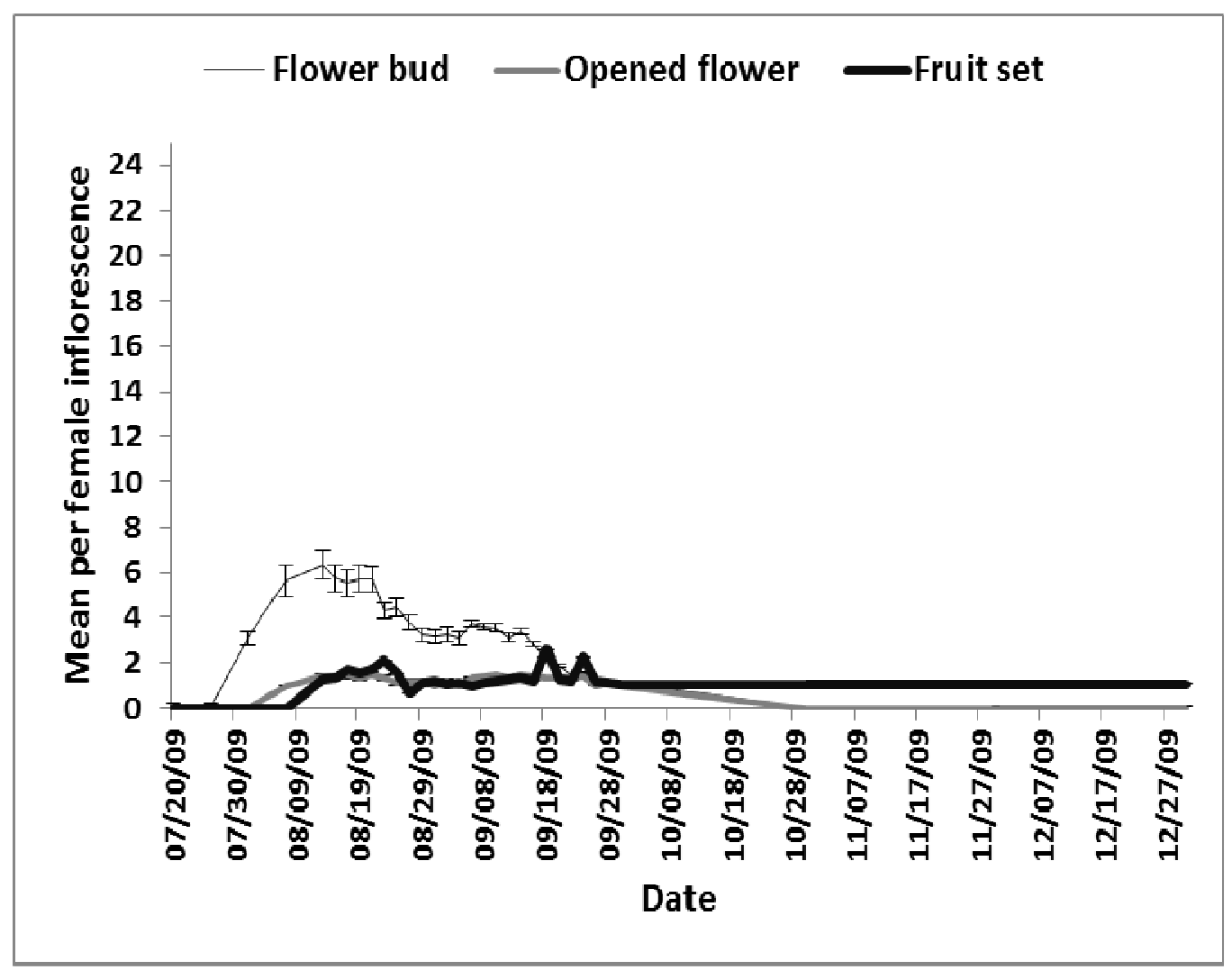

Figure 2: Evolution of flowering and fruiting in female individuals.

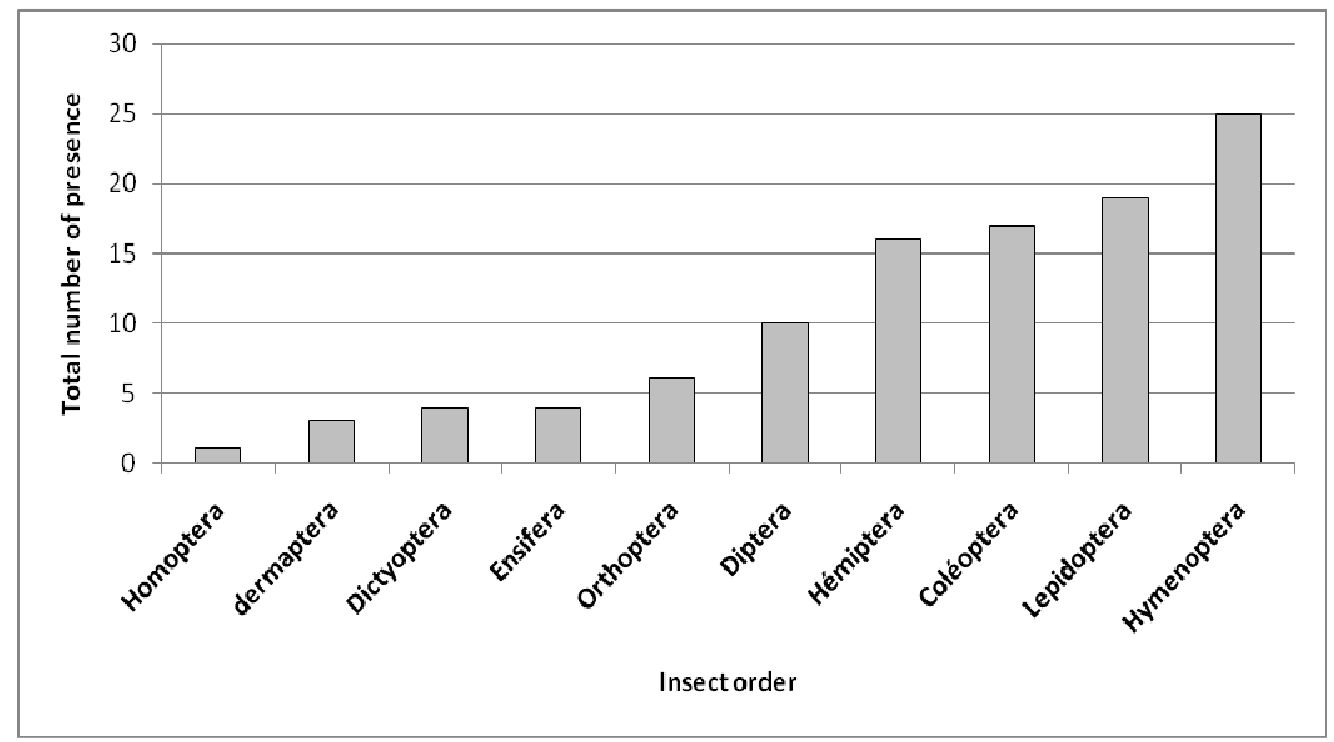

Figure 3: Prevalence of insect orders during flowering time of $P$. reticulatum. 

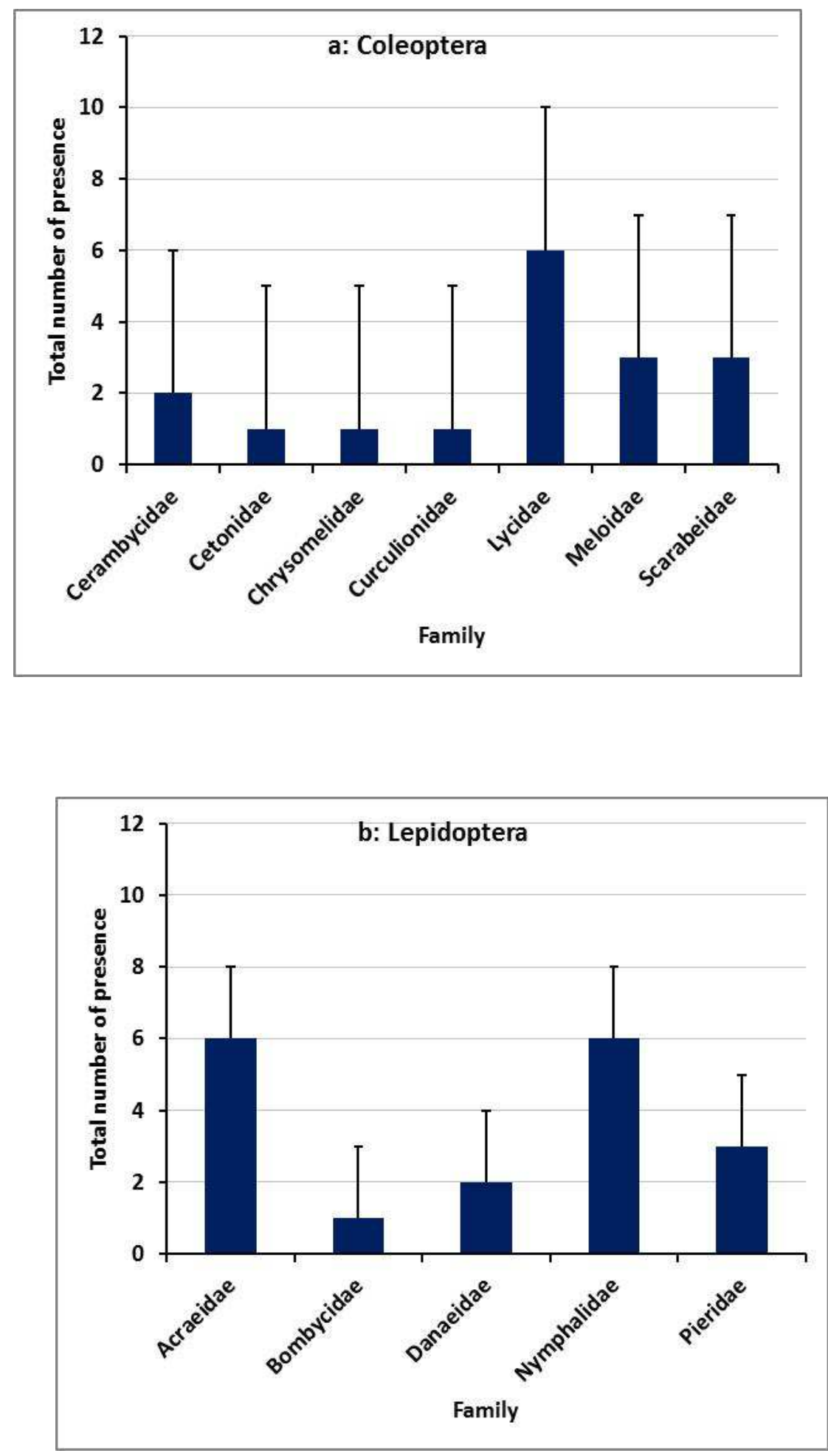

Figure 4: Distribution of insects order during flowering time. 

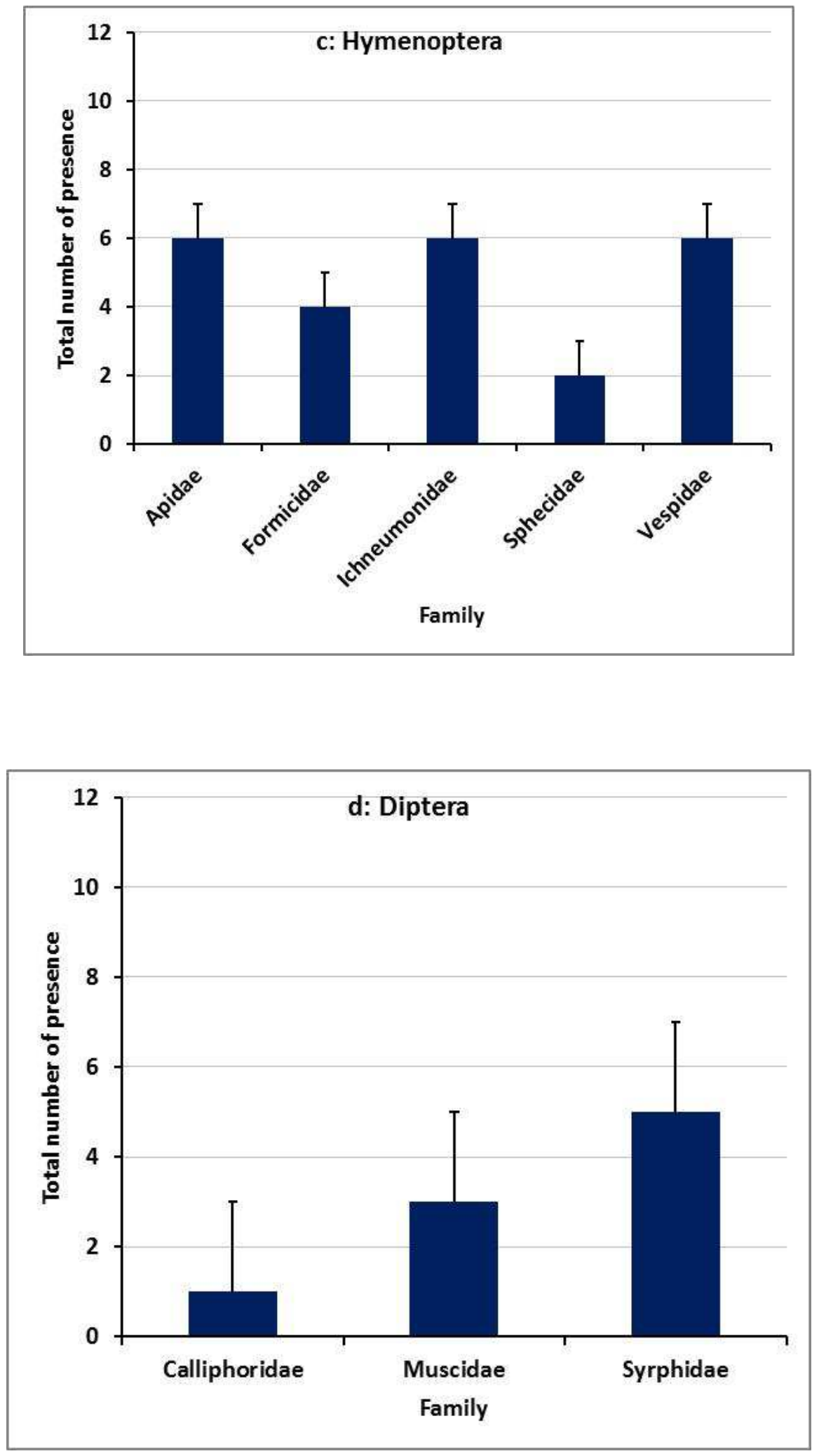


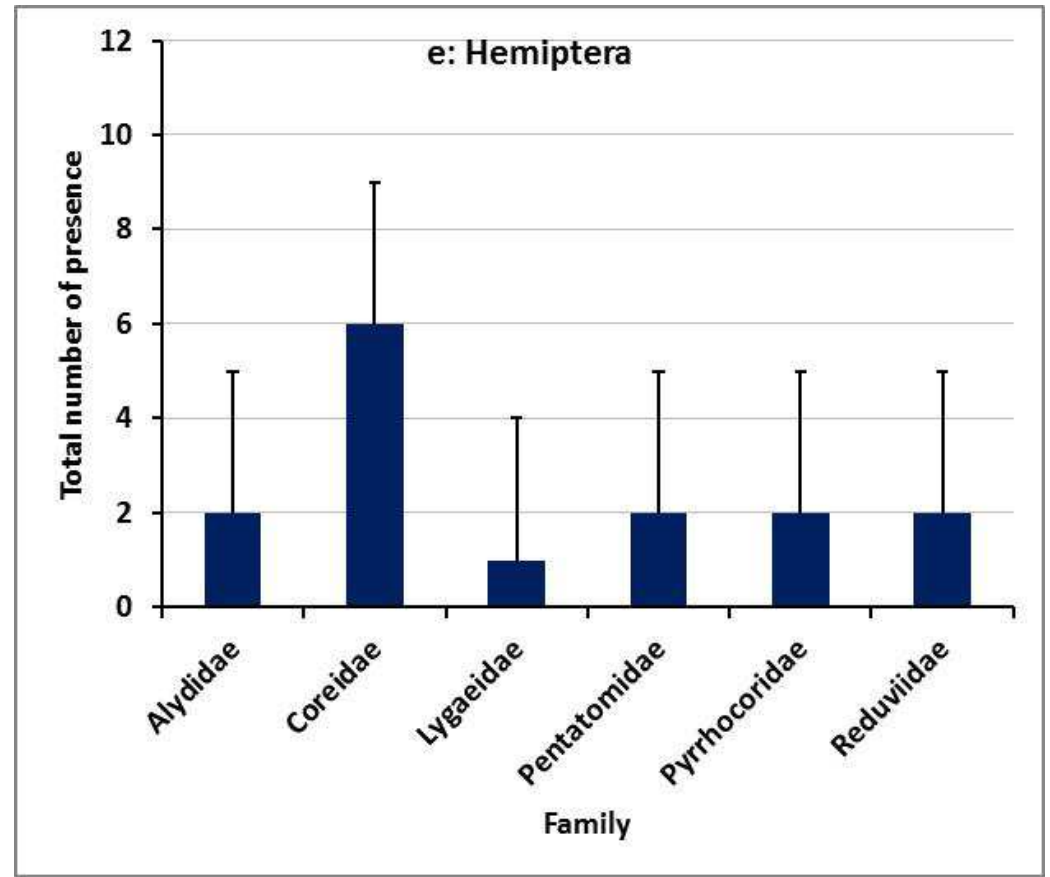

Figure 5: Total number of presence of insects families collected during flowering time. $\mathrm{a}=$ Coleoptera; $\mathrm{b}=$ Lepidoptera; $\mathrm{c}=$ Hymenoptera; $\mathrm{d}=$ Diptera; $\mathrm{e}=$ Hemiptera.

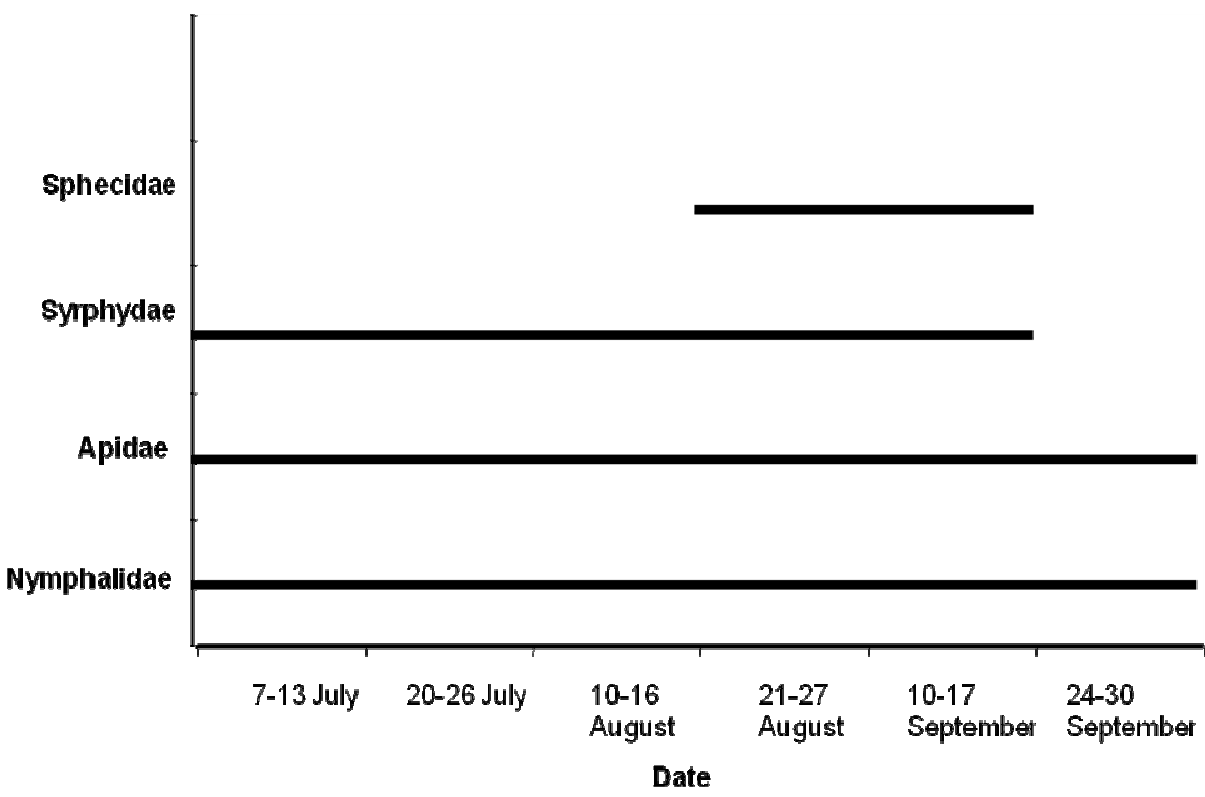

Figure 6: Prevalence of potential pollinators during flowering time. 


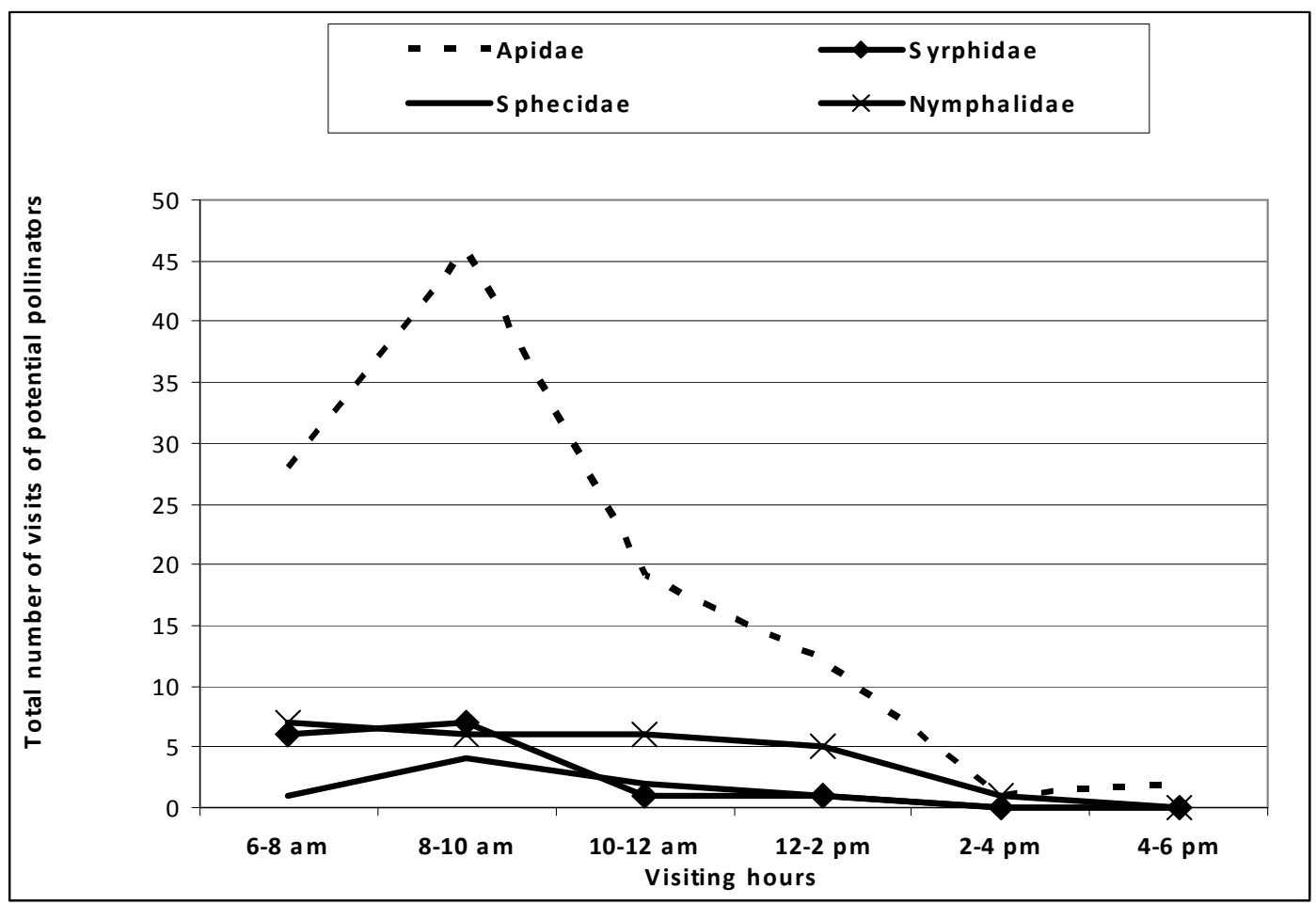

Figure 7 : Evolution of potential pollinator visits from 6 am to $6 \mathrm{pm}$ in August.

Table 1: Floral visitors of Piliostigma reticulatum at Budtenga.

\begin{tabular}{lll}
\hline Order & Family & Genus/Species \\
\hline Lepidoptera & Acraeidae & Acraea bonasia \\
& Danaidae & Danais crisipus \\
& Pieridae & Colotis sp. \\
& Nymphalidae & Characxes epijasius \\
\hline Hymenoptera & Apidae & Apis mellifera \\
& Formicidae & Camponotus sp \\
& Sphecidae & Sceliphron, distillatorium, \\
& & Amophilla sp \\
& Vespidae & Rhopalidia sp, Polistes sp., Vespula sp \\
& Ichneumonidae & Ichneumo sp. \\
\hline Orthoptera & Acrididae & Kraussela amabile, Homoxyrhpes, punctipennis, \\
& & Cataloipus fusiocoeruleipes \\
& & Cataloipus sp., Anacridium sp. \\
& & Humbe tenuicornis, \\
& & Heteropternis thoracica \\
\hline Dermaptera & Forficulidae & Forficula senegalensis, \\
& & Forfucula sp \\
\hline Diptera & Calliphoridae & Stomorhina lunata \\
& Muscidae & Musca sp. \\
\hline Ensifera & Syrphidae & Eristalis sp \\
\hline Homoptera & Ephippigeridae & Ephipigere sp. \\
& Delphacidae & Sogatella cubana \\
& &
\end{tabular}




\begin{tabular}{lll} 
& Lygaeidae & Lygaeus rivularis \\
\hline Dictyoptera & Mantidae & Mantis religiosa \\
\hline Coleoptera & Lycidae & Chamydolicus sp. \\
& Scarabeidae & Quadriciniata sp. \\
& & Charadronata quadrisignata \\
& Campsura sp., Xeloma sp. \\
& Polybaphes sanguinobenta \\
& Polybaphes acquinoctialis \\
& Pacnoda cordata, Pacnoda marginata. \\
& Cerambycidae & Phryneta aurocincta, Crossotus sp \\
& Meloidae & Psalydolitta fusca, Mylabris oloserica, Psalydolytha Theresa \\
& Curculionidae & Sitona lineatus \\
& Chrysomelidae & Asbecesta capensis \\
\hline Hemiptera & Pyrrhocoridae & Dysdercus völkeri \\
& Coreidae & Anoplocnemis curvipes \\
& Alydidae & Mirperus jaculus \\
& Reduvidae & Cosmolestes pictus \\
& Pentatomidae & Aspavia armigera \\
\hline
\end{tabular}

\section{DISCUSSION}

$P$. reticulatum blooms once a year during the rainy season. Flowering at the beginning of the rainy season is a common characteristic of tree species observed in the Sudanian and Sahelian areas (Dao et al., 2006). The flowers opened not simultaneously in both individuals, but a synchronism in the peak of flowering was noted between them. Male individuals bloom almost two weeks earlier than the female ones. Flowering in the beginning is characterized by a lack of synchronism between male and female individuals. Peak flowering occurred on both individuals (male and female) simultaneously on August. The end of flowering occurred also on both plants simultaneously on September. The lack of synchrony in the beginning of flowering is in contrast with the previous studies on the other species of Caesalpinioïdeae (Tamarindus indica) in the Sudanian and Sahelian areas (Diallo, 2008).

We found that $P$. reticulatum blooms from July to October (about 4 months). This blooming duration may increase the availability of pollen and nectar resources for long period and promote the attractiveness of pollinators.

$P$. reticulatum male individuals bloom more than female ones. Previous studies have found that male flowers of $P$. reticulatum do not produce fruits and they are considered to be pollen donors in the population (Dao, 2012)

Sommer (1986) evaluated five hypotheses concerning the overproduction of flowers in $H$. virginiana and concluded that attraction of pollinators was the likely cause for such situation. Female individuals produce fruit continuously from August to December and the maturity occurs on December during the dry season. A female infrutescence produces less than two fruits. So many flowers are dropped before fruit set. Losses are important; this might be explained by extrinsic factors such as florivory which can decrease plant fitness.

$P$. reticulatum is visited by 31 families of insects belonging to 10 orders. The diversity of floral visitors can be explained by the availability of plant rewards. These rewards are likely to be pollen and/or nectar as it is usually observed in dioecious species.

Nymphalidae (Lepidoptera), Syrphidae (Diptera), Apidae (Hymenoptera) and Sphecidae (Hymenoptera) are considered as potential pollinators because they are nectarivores and/or pollinivores and also because of their ability to carry pollen and / or to stimulate the receptivity of stigma (Diallo, 2008). Previous studies indicated that Diptera and Hymenoptera were the primary floral visitors and pollen carriers (Sahli and Conner, 2007). It is reported that Hymenoptera, 
Diptera and Lepidoptera visit flowers to feed on nectar and pollen and several of these carry pollen on their bodies (Burkle et al., 2013). At the family level, Nymphalidae (Lepidoptera), Syrphidae (Diptera), Apidae (Hymenoptera) and Sphecidae (Hymenoptera) were often dependent of floral rewards and their bodies were equipped to carry pollen (Anderson and Hill, 2002).

Our result indicates that the peak of flowering of both individuals in August is synchronic with the high activity of potential pollinators of $P$. reticulatum. Given the variety of insect visitors of $P$. reticulatum and the long timing of flowering of this species, high production of flowers to attract pollinators seemed a likely explanation within the context of the dioecious system. The diversification of pollinators decreased the limited resources problem and might be an important factor for successful pollination. According to Knight et al. (2005), the diversity of pollinators could result in a diversity of pollen grains transferred to the stigma of the flower as from different donors. It was also demonstrated that the success of the fruit of Coffea arabica increases proportionally with the diversity of pollinators (Klein et al., 2003). However, some studies did not confirm this thesis. When there are more pollen donors, the quality of pollen transferred to the stigma is decreasing (Sahli and Conner, 2007).

Apidae and Nymphalidae emerged and gathered pollen from the beginning to the end of flowering of $P$. reticulatum. They are considered as permanent pollinators. Sepsidae emerge only in August, they are considered as occasional pollinators. Syrphidae appeared early (in July) and was absent at late flowering. This indicates that there is a temporal overlap of the potential pollinator's activity during the flowering period of $P$. reticulatum. When we consider the daily distribution of potential pollinators, Apidae family is the most frequent visitor at early, warm and dusk hours. Nymphalidae and Syrphidae are the warm hour flowers visitors. However, previous studies on tamarind showed that the families Nymphalidae and Syrphidae were only early and dusk hour visitors (Diallo, 2008). Therefore, the organization of floral visits could vary from one species to another. In conclusion, $P$. reticulatum produces flowers from July to September. The loss of flowers buds is important and the fruit set is low. The peak production of flowers in August is more synchronous with the intensive activity of potential pollinators. Nymphalidae, Syrphidae, Sphecidae and Apidae are considered as the potential pollinators of $P$. reticulatum. It is not specialized for one pollinator species. These potential pollinators get organized to visit flowers during the 3 months of flowering and also through the day. Apidae family is the most frequent potential pollinator.

\section{Conclusion}

$P$. reticulatum flowers are attractive to a variety of visitors and pollinators. The fact underlines the importance of this species in the maintenance of general insect biodiversity in the Tropical dry forest.

\section{ACKNOWLEDGEMENTS}

We thank Ouedraogo M. and Traore M. for insect identification supervision, Bonkoungou A.; Zagre M. and Ouedraogo L. for the field assistance. Partial research support was provided by ICRAF Bamako.

\section{REFERENCES}

Anderson G, Hill JD. 2002. Many to flower, few to fruit: the reproductive biology of Hamamelis virginiana (Hamamelidaceae). American Journal of Botany, 89(1): 67-78.

Arbonnier M. 2009. Arbres, Arbustes et Lianes des Zones Sèches d'Afrique de l'Ouest ( $3^{\text {ème }}$ édn revue et augmentée). MNHN-QUAE; $576 \mathrm{p}$.

Bawa KS, Buckley DP. 1989. Seed ovule ratios, selective seed abortion and mating systems in Leguminosae. Advances in legume biology. In Monographic, Systematic and Botanic, Stirton C, Zarucchi JL (eds). Missouri Botanic Gardens: Kew; 466p.

Burkle LA, Martin, JC, Knight TM. 2013. Plant pollinator interactions over 120 years: loss of species, co-occurrence, and function. Science, 339: 1611-1615. 
Caban FJ, Melendez-Ackerman J. 2007. Relative pollination effectiveness of floral visitors of Pitcairnia angustifolia (Bromeliaceae). American Journal of Botany, 94(3): 419-424.

Chinery M. 1986. Le Multiguide Nature des Insectes d'Europe en Couleurs. Edit. Bordas: Paris; 380 p.

Dao M, Diallo BO, Tamini Z, Bastide B, Guinko S. 2006. Evolution de la morphologie florale chez Ziziphus mauritiana Lam. (Rhamnacae): mouvements des pièces florales et des étamines. Cameroon Journal of Experimental Biology, 2(2): 70-76.

Dao MCE, Diallo BO, KABOREZOUNGRANA C. 2010. Hermaphrodisme morphologique et dioécie physiologique dans une population de Piliostigma reticulatum (D C) Hochst (Ceasalpinioidae. Cameroon Journal of Experimental Biology, 6(1):21-30.

DAO MCE, DIALLO BO, KABOREZOUNGRANA C. 2012. Fruit and seed production in a natural population of a dioecious plant: Piliostigma reticulatum HOCHST (Caesalpinioïdeae). Int. J. Biol. Chem. Sci. 6(1): 11-23.

De Bie S, Ketner P, Breerling C. 1998. Woody plant phenology in West Africa savannah. Journal of Biogeography, 25: 883-900.

Denisow B. 2009. Factors determining diurnal dynamics of blooming of chosen plants species. Acta Agrobot., 62(1): 83-89.

Diallo BO, Doyle Mckey, Marie-Hélène Chevallier, Hélène IJ, Hossaert-Mckey M. 2008. Breeding system and pollination biology of the semi-domesticated fruit tree, Tamarindus indica L. (Leguminosae: Caesalpinioideae). African Journal of Biotechnology, 7(22), 4068-4075.

Guinko S, Fontes J. 1995. Carte de la végétation et d'occupation du sol du Burkina Faso. Notice explicative. Ministère de la coopération française, Projet Campus, Toulouse, France, 67p.
Hedhly A, Hormaza JI, Herrero M. 2008 Global warming and plant sexual reproduction. Trends Plant Sci., 14: 3036.

Ibrahim B, Polcher J, Karambiri H, Rockel B. 2011. Characterization of the rainy season in Burkina Faso and it's representation by regional climate models. Climate Dynamic, 39(6): 1287-1302.

Klein AM, Steffan-Dewenter I, Tscharntke T. 2003. Fruit set of highland coffee increases with the diversity of pollinating bees. Proc. R. Soc. Lond., Ser. B, 270: 955-961.

Knight TM, Steets JA, Vamosi JC, Mazer SJ, Burd M. 2005. Pollen limitation of plant reproduction: pattern and process. Annual Review of Ecology Evolution and Systematics, 36: 467-497.

Ollerton J, Winfree R, Tarrant S. 2011. How many flowering plants are pollinated by animals? Oikos, 120: 321-326.

Picker M, Griffiths C, Weaving A. 2004. Field Guide to Insects of South Africa. Struik Nature: South Africa; 437 pp.

Reed W, Lateef SS, Sithanantham S, Pawar CS. 1989. Pigeonpea and Chickpea Insect Identification Handbook. Information Bulletin $N^{\circ}$ 26. ICRISAT: India; 120.

Sahli HF, Conner J. 2007. Visitation, effectiveness, and efficiency of 15 genera of visitors to wild radish, Raphanus raphanistrum (Brassicaceae). American Journal of Botany, 94(2): 203-209.

Sommer SA. 1986. The pollination ecology and breeding system of Hamamelis virginiana L. (Hamamelidaccae). M.S. Thesis, University of Maryland. College Park, Maryland, USA.

Yelemou B, Zougmoré R, Bationo BA, Millogo-Rassolodimbi J, Hien V. 2009. Phenology and fruit production of Piliostigma reticulatum (DC) Hochst., an agroforestery forage species in the Sahel. Cameroon Journal of Experimental Biology, 5(1): 10-20. 